\title{
PRÁTICAS DE LEITURA E CENTRALIDADE DAS IMAGENS
}

\author{
Reading practices and centrality of images \\ Prácticas de lectura y centralidad de las imágenes
}

Vera Lúcia Follain de Figueiredo Professora do Programa de Pós-Graduação em Comunicação da PUC-Rio verafollain@gmail.com

Marina Burdman da Fontoura Doutoranda em Comunicação pela PUC-Rio marina.burdman@gmail.com

\section{Resumo}

Ainda que a existência de uma centralidade da experiência visual na cultura contemporânea não deixe de gerar controvérsias, alguns estudiosos têm celebrado o que chamam de giro icônico, reivindicando, para as imagens, direitos iguais aos da linguagem, e não simplesmente serem transformadas em linguagem. $\mathrm{O}$ artigo discute esta questão a partir das mudanças ocorridas nas práticas de leitura com a expansão da tecnologia digital, considerando o crescente protagonismo do mercado como mediador cultural.

Palavras-chave: Imagem. Práticas de leitura. Mercado.

\begin{abstract}
Although the centrality of visual experience in contemporary culture is controversial, some scholars have been celebrating what they call the iconic turn, claiming for the images the same rights as for the language, and not simply the transformation of images into language. The present article discusses this from the standpoint of changes in reading practices brought about by the expansion of digital technology and the central role played by the market in culture mediation.
\end{abstract}

Key words: Image. Reading practice. Market.

\section{Resumen}

Aunque la existencia de una centralidad de la experiencia visual en la cultura contemporánea no está exenta de controversia, algunos académicos han celebrado lo que llaman un recorrido icónico, reclamando, para las imágenes, la igualdad de derechos al lenguaje, y no simplemente transformándose en lenguaje. El artículo analiza este tema en función de los cambios en las prácticas de lectura con la expansión de la tecnología digital, en vista del papel del mercado como mediador cultural.

Palabras clave: Imagen. Prácticas de lectura. Mercado. 


\section{INTRODUÇÃO}

Ainda que a existência de uma centralidade da experiência visual na cultura contemporânea não deixe de gerar controvérsias, algumas correntes de pensamento, que vêm ganhando força no campo da produção teórico-crítica ao longo das primeiras décadas do século XXI, têm destacado o status da imagem não só como modo de representação, mas também como base para a construção do pensamento. Faz-se referência, aqui, à expansão do campo interdisciplinar dos chamados Estudos Visuais, a partir da década de 1990, principalmente, nos Estados Unidos e na Inglaterra - campo de investigação que parte do reconhecimento de que os conceitos vigentes de visualidade e discursividade são produtos de uma longa tradição filosófica que precisaria ser revista em função das importantes mudanças tecnológicas, culturais e epistemológicas ocorridas a partir do final do século passado ${ }^{1}$.

$\mathrm{Na}$ esteira de uma requalificação da imagem contra o que se considera uma iconoclastia da crítica, estudiosos como, por exemplo, Gerhard Richter, rechaçam a análise semiótica das imagens característica da década de 1980, porque dependeria de um modelo linguístico, considerando que as imagens têm uma presença que escapa a nossa competência linguística para descrever ou interpretar. As imagens e as palavras, ainda que intimamente relacionadas, seriam ordens de conhecimento que não podem ser equiparadas. Para Mitchell, as imagens querem direitos iguais aos da linguagem: "a visão é tão importante quanto a linguagem na mediação de relações sociais sem ser, no entanto, redutível à linguagem, ao signo ou ao discurso" (2015, p.186).

Também na perspectiva filosófica, a imagem tem adquirido cada vez mais prestígio, sendo vista como um contraponto aos encadeamentos sequenciais, teleológicos, totalizantes e, nesse sentido, considerada como uma espécie de trincheira de onde se oferece resistência às continuidades impostas pela cultura da escrita. Afirma-se, desse modo, um outro olhar: se no momento da chamada virada linguística tudo era visto como texto, agora, segundo determinada vertente teórica, tudo deve ser percebido como imagem. Na convicção de que haveria, na atualidade, uma hegemonia do visível, um domínio dos meios visuais e do espetáculo sobre as atividades da fala, da escritura e da leitura, anuncia-se a ocorrência de um "giro das imagens", "giro icônico" ou "giro visual", conforme se prefira chamar. De acordo

\footnotetext{
${ }^{1}$ As controvérsias em torno da questão atualizam, a seu modo, os embates entre palavra e imagem que pontuaram historicamente a trajetória de diferentes culturas. Para maior aprofundamento do tema, veja-se o texto MITCHELL,W.J.T. Showing seeing: a critique of visual culture. Journal of Visual Studies (London), v.1, n.2, p. 165-82, 2002.
} 
com Wajcman, por exemplo, estaríamos diante de uma nova civilização na qual a máquina de ver é a cultura mesma e tudo deve ser visível (2011, p 15).

Apesar da dificuldade de se definir claramente o que viria a ser "cultura visual", as discussões relativas à hegemonia da visualidade, pelo menos em certos setores do mundo acadêmico, como o da História da Arte, vêm ocupando lugar de destaque, mesmo que, paradoxalmente, as artes visuais cada vez mais recorram às palavras para expressar a ideia que as constitui, isto é, que haja uma proeminência da linguagem verbal no próprio campo da criação visual.

A virada pictórica, entretanto, não significaria apenas uma "redenção justa da imagem", para usar a expressão de Rancière (2013), ou uma volta do recalcado, mas também a possibilidade de investigação do entrelaçamento do visual com os outros sentidos, considerando-se que não há objetos ou fenômenos de visualidade pura: os atos de ver resultariam de uma complexa construção tributária do entrecruzamento de operadores textuais, mentais, sensoriais, midiáticos, institucionais (Brea, 2011, p.9). Ressalta-se o caráter cultural, político dos atos de ver, que ganham relevo pelos seus efeitos performativos associados à produção de imaginário. A ideia predominante é que, com a transformação das tecnologias da visão, a primazia, no mundo contemporâneo, seria dos atos de ver, não dos atos de ler, e a imagem teria se convertido em depositária da função epistemológica:

\begin{abstract}
Aborrecidos do giro linguístico e da ideia de que a experiência está filtrada por meio da linguagem, muitos estudiosos estão agora convencidos de que podem ter acesso imediato ao mundo que nos rodeia, que a distinção sujeito/objeto, por longo tempo um selo distintivo da empresa epistemológica, já não é válida. Na urgência de dar sentido às circunstâncias nas quais nos encontramos, nossa tendência no passado foi ignorar e esquecer a presença em favor do sentido. Foram lançadas interpretações sobre os objetos para domesticá-los, para tê-los sob controle, dotando-os com significados que não possuem necessariamente. (MOXEY, 2003, p.2)
\end{abstract}

\title{
2 DESENVOLVIMENTO
}

Diante de tal crítica à cultura da escrita, associada ao prognóstico de que as textualidades estariam perdendo espaço para as visualidades, somos levados a indagar o futuro da literatura e, mais especificamente, do mercado editorial. A literatura ainda será, intrinsecamente, a arte do livro, como tem sido definida? O termo literatura passará a abranger uma produção cujo principal meio de expressão não é necessariamente a palavra escrita? Como conceituar o próprio livro e como tudo isto reconfigura as noções de obra e 
autoria? Enfim, quais as estratégias usadas pelo mercado editorial diante da expansão das escritas hipermidiáticas?

Tendo em mira essas questões, nota-se na produção literária contemporânea, uma crescente importância dos chamados paratextos editoriais, que deixam de ter uma função prioritariamente editorial e passam também a dialogar de forma criativa com as obras literárias. Se, quando Gérard Genette os classificou como aparatos que giram em torno do texto principal de um livro (2009), eles ainda estavam restritos à plataforma impressa e à televisão, hoje, com a popularização do computador, eles ganham outros formatos. Nesse caso, a imagem aparece como um importante modo de divulgar livros por meio de booktrailers e outros vídeos institucionais, e também como uma possível maneira de estabelecer relações diversas com o conteúdo impresso: o que se torna evidente, por exemplo, com a criação de páginas no Facebook para personagens de livros e de postagens de escritores em redes sociais pictóricas, como o Instagram, com o objetivo de criar tramas que dialoguem com o conteúdo publicado no meio impresso. Os paratextos, excedendo as fronteiras do livro físico, e, sem as limitações impostas pela sua materialidade, podem se apresentar também no formato audiovisual. O aumento de popularidade dessas imagens no meio literário, que chegam a milhares de acessos e compartilhamentos, é tamanho que nos leva a perguntar até quando a palavra conseguirá manter sua hegemonia no que se refere ao campo da literatura.

$\mathrm{Na}$ tela do computador, como se sabe, o texto convive lado a lado com a imagem e acaba por perder sua centralidade, estabelecendo outros tipos de relação com o conteúdo audiovisual ali presente. ${ }^{2}$ No ambiente digital, portanto, vídeos, fotografias e áudios integram o campo literário e ajudam a consolidar, paradoxalmente, uma cultura visual em meio a um número cada vez maior de textos em circulação. A revista eletrônica CAIS, por exemplo, tira partido das potencialidades do suporte, trazendo textos literários, ilustrações, fotografias, vídeos, áudios, músicas e gifs, isto é, explorando toda a gama de possibilidades comunicacionais e expressivas do formato digital. Trata-se de uma publicação que visa, sobretudo, a divulgar obras de escritores jovens, sendo definida por sua idealizadora, Luana Carvalho, do seguinte modo:

CAIS é um espaço de residência artística virtual que considera todos os possíveis desdobramentos e formatos da escrita em língua portuguesa. Um

\footnotetext{
${ }^{2}$ Embora um livro reproduzido nas plataformas digitais, sob determinados critérios, não deixe de ser um livro, consideramos, com Roger Chartier, que não há texto fora do suporte que o dá a ler (ou a ouvir) e que "não existe a compreensão de um texto, qualquer que ele seja, que não dependa das formas através das quais ele atinge o seu leitor". (2002, p. 17)
} 
espaço de experimentação para trabalhos inéditos e aprofundamento de pesquisas continuadas. São colunistas recorrentes ou extraordinários a cada edição, num fluxo contínuo entre som, imagem, palavra e movimento, um transe, um lance. CAIS vem da imagem de uma avenida paralela ao mar, onde embarcam e desembarcam coisas e gentes. É casa, é viagem, é passagem. ${ }^{3}$

Ainda tratando da produção literária no computador, se pensarmos sobre algumas obras feitas exclusivamente para essa plataforma, mais uma vez nos deparamos com uma reconfiguração do que entendemos tradicionalmente como literário. Um exemplo disso é a chamada literatura eletrônica, que, diferentemente de alguns textos que migram ou são adaptados para outros suportes, é produzida exclusivamente para o computador e feita para ser lida apenas nessa plataforma: ou seja, não se trata somente de um texto veiculado na plataforma digital, mas, sim, de um conteúdo cuja produção só é possível nesse meio. Como explica Katherine Hayles, o texto de literatura eletrônica é um produto híbrido, que herda características de diversas áreas e desenvolve também procedimentos próprios. Ela afirma:

Ao mesmo tempo, e porque a literatura eletrônica é normalmente criada e executada em um contexto de rede e meios de comunicação digital programáveis, ela também é movida pelos motores da cultura contemporânea, especialmente jogos de computador, filmes, animações, artes digitais, desenho gráfico e cultura visual eletrônica. Nesse sentido, a literatura eletrônica é um "monstro esperançoso" (como os geneticistas chamam as mutações adaptativas) composto por partes extraídas de diversas tradições e que nem sempre se posicionam juntas e de forma organizada. (2009, p. 21)

Nota-se, então, uma clara semelhança entre alguns trabalhos desse tipo e o videogame ou os jogos de computador. Hayles, citando a ficção interativa, em que o jogador/personagem é chamado pelo termo "interator", ressalta que "a demarcação entre literatura eletrônica e jogos de computador não é clara; muitos jogos têm componentes de narrativa, ao passo que muitas obras de literatura eletrônica têm elementos de jogo" (2009, p. 25). A diferença, no entanto, estaria no foco de cada um, sendo o trabalho com a narrativa o foco do objeto de literatura eletrônica.

Em palestra intitulada "A literatura na época de sua infinita reprodutibilidade técnica", apresentada no Encontro Entre TELAAS ${ }^{4}$ (UNB, 2016), Jéferson Assumção chamou a atenção para os efeitos no sistema literário, isto é, no triângulo autor/obra/público, da desmaterialização dos suportes da arte. Para o pesquisador, estamos diante de uma crise das instâncias tradicionais de legitimação, que se encontram pressionadas por uma nova instância,

\footnotetext{
${ }^{3}$ Disponível em http://cais.ato.br/sobre/ Consulta em 18/12/2017.

${ }^{4}$ Disponível em https://www.youtube.com/watch?v=WH6-P49V6uY. Consulta em 18/12/2017.
} 
a do comum, cuja força advém das redes digitais e que se expressa através de curtidas, de likes. Para Assumção, na era da banalidade das cópias, é preciso repensar a performance do escritor, lembrando (como já assinalava Chartier na década de 1990) que, na verdade, "o autor não faz livro, quem faz livro é o editor: o autor faz literatura, faz narrativas que podem estar em qualquer lugar, como, por exemplo, nos games". O escritor teria, assim, diversos espaços para se expressar, passando por cima das fronteiras dos suportes.

Tais deslizamentos geram novas relações com o escrito e novas práticas intelectuais. Assim, o que chamamos de convergência de mídias também diz respeito a alterações nos modos de ler, estimulando o comportamento migratório do público midiático, instado a migrar de um suporte a outro seguindo o fluxo de conteúdo por múltiplas plataformas em busca de experiências renovadas de entretenimento. Por isso, Chartier afirma que "a revolução iniciada é, antes de tudo, uma revolução dos suportes e das formas que transmitem o escrito" (CHARTIER, 1999, p.40).

Inserido nesse contexto de interações cada vez mais complexas entre as plataformas, o autor se torna ele próprio uma figura multimídia, estando presente não só nos livros, mas também em jornais, na televisão, em feiras literárias e principalmente em páginas online. Os escritores fazem uso de imagens dispostas nessas plataformas não só para fins criativos, mas também para chamar atenção para suas figuras e, consequentemente, para sua produção. Assim, a mediação entre obra e leitor cabe menos a avaliações de críticos ou a matérias na imprensa e passa a ser papel também do próprio escritor.

O mercado editorial brasileiro, por sua vez, também vem se utilizando de recursos virtuais para promover autores de seus catálogos. Um exemplo mais recente disso pode ser visto com a campanha "Leia em Casa", feita pela Companhia das Letras em consequência da necessidade de postergação da agenda de eventos da editora por causa do coronavírus. A programação conta, entre outras coisas, com diários de isolamento e diversas lives feitas por escritores. Luisa Geisler, Noemi Jaffe e Lilia Moritz Schwarcz são alguns dos autores que passaram pelo Instagram e YouTube da editora no período de isolamento.

Desse modo, a preferência do público por um autor, como mostra Philippe Lejeune, pode acontecer antes mesmo que se tenha lido alguma de suas obras. O leitor muitas vezes acompanha a vida de autores por meio de textos e paratextos no ambiente digital, tendo acesso a detalhes da vida pessoal antes de entrar em contato com sua produção impressa. Segundo o teórico francês, se antes conhecíamos a obra e imaginávamos o autor, hoje a tendência é conhecermos o autor para imaginarmos a obra, que muitas vezes não leremos: 
Na televisão, enfim, voz e imagem se reuniram. Nada mais a ser imaginado: o autor do livro que lemos ou, com mais frequência, do livro que não lemos e que não leremos está ali, em carne e osso e ao vivo. Se ainda restar algo a ser imaginado, será, paradoxalmente, o que ele terá escrito. (LEJEUNE, 2008, p.194)

Além de promover seu trabalho e falar sobre a própria vida, o autor passa a opinar também sobre outras produções, como livros e filmes, e acaba exercendo uma função que antes cabia preferencialmente aos críticos: escritores aparecem em programas e canais do YouTube para comentar trabalhos de outras pessoas, como é o caso da série Livro de cabeceira, veiculada no canal do YouTube "Esquina Cultural". Nela, vinte autores brasileiros apontam os livros favoritos e mostram quais obras teriam influenciado suas escritas. Nesse caso, mesmo que o nível de aprofundamento das análises não pretenda ser o mesmo do crítico tradicional, o escritor acaba por cumprir a função de despertar o interesse do público por um determinado trabalho.

Portanto, para além da crescente interseção dos campos da produção cultural contemporânea, as funções do autor, do crítico e do editor estão cada vez menos claras e definidas na literatura. As fronteiras entre a esfera da produção do livro e a da criação artística também se misturam, e o autor se vê ainda mais imerso no mercado de editoração, participando de projetos, colunas, trailers e outros vídeos institucionais: "o artista, cuja formação tende a ser multimídia, trabalha, então, com mensagens de diversas séries literárias, visuais, musicais" (Figueiredo, 2010). Nesse cenário, o leitor se desloca entre textos online e off-line, acompanha produtos feitos para serem lidos em diversas mídias e passa, então, a conhecer mais sobre a vida e o trabalho do autor a partir de informações que chegam a ele com mais facilidade por causa da internet. Tanto nas obras impressas, com o aumento da popularidade de narrativas autobiográficas e autoficcionais, quanto na divulgação feita nas redes sociais e na televisão, a imagem e os pensamentos dos autores aparecem como um meio de atrair o público. Essa migração de leitores entre plataformas decorre, muitas vezes, do esforço do mercado editorial para fazê-los acompanhar a trajetória e as opiniões de um escritor específico.

Para entender melhor o papel do mercado editorial nesse cenário, é preciso levar em conta a sua importância cada vez maior como mediador cultural no campo literário. Importância que se revela no lançamento de projetos que dão origem a livros escritos sobre encomenda, nos incentivos de editoras a festas literárias e em ações variadas em plataformas digitais. Também não se pode deixar de notar o significativo papel que as redes sociais 
desempenham para a manutenção dessa lógica ambígua: ao mesmo tempo em que podem servir como uma ferramenta para certa espetacularização da figura do autor, também podem servir como um meio de ampliar e, portanto, de democratizar o acesso à informação.

Por isso, não se pode afirmar que esse aumento do número de textos e paratextos na internet serve somente ao mercado - a produção e o investimento nesses produtos não se dão com o único intuito de aumentar o número de vendas dos livros impressos. Quando um autor se propõe a participar de projetos e vídeos em redes sociais, ele não está, necessariamente, atuando apenas segundo uma estratégia de marketing, mas também pode ter como objetivo aumentar o alcance de sua obra com a intenção de que mais pessoas possam desfrutar de experiencias literárias. Ou seja, as plataformas digitais servem à democratização do acesso à informação sem que deixem de servir também como um meio de os autores e as editoras ganharem dinheiro com suas publicações.

Há, entretanto, diversas maneiras de utilizar ferramentas oferecidas por essas plataformas. Torna-se comum, por exemplo, a presença de autores reconhecidos pela crítica em sites e nas páginas das redes sociais, onde leem trechos de suas obras e divulgam seus lançamentos. Para destacar apenas alguns dos muitos exemplos possíveis de livros publicados recentemente, pode-se citar Como se estivéssemos em palimpsesto de putas (2016), da escritora Elvira Vigna, que, por ocasião do lançamento, participou de um vídeo postado no canal da Companhia das Letras no YouTube. Com uma música de fundo e um cenário composto por uma estante de livros, ela leu um trecho de seu novo romance. Também o escritor Bernardo Carvalho participou de vídeo com formato semelhante, em que lê por mais de seis minutos um trecho de Simpatia pelo demônio (2016).

Além deles, outros autores, como Michel Laub e Daniel Galera, tiveram lançamentos divulgados nas redes sociais. Para promover Meia noite e vinte (2016), Galera apareceu em uma foto publicada no Instagram da Companhia das Letras sorrindo e apontando para o livro. No Facebook da mesma editora, é possível ver uma postagem fazendo referência ao romance O tribunal da quinta-feira (2016), de Laub, que convida o leitor a conhecer a capa do livro, que seria lançado no mês seguinte e já se encontrava em pré-venda. Ao observar esses casos, não se pode deixar de notar que a produção de grande parte desses produtos vem de iniciativas do grupo Companhia das Letras, que, além de ter um catálogo extenso de escritores, também mostra uma preocupação em divulgar livros em plataformas digitais. Constituindo-se numa grande corporação editorial, o grupo investe no marketing de seus livros e mostra dominar diferentes modos de chamar a atenção do leitor a partir da utilização 
de páginas online. Pode-se afirmar, assim, que o mercado editorial brasileiro, protagonizado por essa editora, tem investido cada vez mais nessas plataformas e busca, a partir delas, garantir bons lançamentos para seus livros.

Hoje, portanto, como a separação entre arte e mercado não se pretende rígida, torna-se mais comum autores preocupados com o reconhecimento artístico fazerem concessões a interesses comerciais. John B. Thompson, no livro Mercadores de cultura (2013), analisa o surgimento das grandes corporações editoriais, principalmente nos Estados Unidos, e mostra como um cenário composto por editoras independentes passou, pouco a pouco, a ser dominado por grandes empresas. Com essa mudança no mercado editorial, também as estratégias de divulgação dos livros sofrem alterações.

Para ele, é preciso saber como chamar a atenção do leitor em meio a um lançamento incessante de títulos. Haveria, no marketing editorial, uma perda de hegemonia das mídias tradicionais de massa e, em contraposição, o que chama de "micromídia" teria se tornado um canal-chave para a publicidade de livros. Desse modo, ainda que os meios tradicionais de massa continuem sendo importantes para chamar a atenção dos leitores, vê-se o surgimento de novos canais que estimulam outros modos de divulgação de obras literárias. Blogs, sites e páginas em redes sociais, por exemplo, tornam-se meios essenciais para entrar em contato com o leitor e convidá-lo a conhecer autores e livros. Thompson mostra, inclusive, mudanças no tempo de divulgação dos livros, que atualmente, com as novas mídias, começa antes mesmo do lançamento (2013, p. 271).

Essa nova estratégia pode ser percebida no cenário brasileiro se observarmos a grande quantidade de trailers e teasers - que tradicionalmente promovem obras audiovisuais - de obras literárias, geralmente divulgados bem antes do lançamento dos livros físicos. Também é possível notar movimento semelhante se observarmos algumas colunas de autores em blogs e sites de editoras, que, apesar de nem sempre serem fruto de uma estratégia da editora para divulgar livros, cumprem essa função ao despertar a curiosidade dos leitores para as obras antes mesmo de seu lançamento. Assim, cria-se a expectativa do lançamento em pessoas que Thompson chama de leitores em potencial, e o marketing passa a ser feito também por intermediários como blogueiros, youtubers e outros leitores que circulam pelas redes sociais.

Segundo o autor, qualquer menção ao livro feita na Web é válida, já que, nesse ambiente, tudo fica indexado e, quanto mais um autor ou obra for citado, melhor será a possibilidade de acesso ao seu trabalho. Thompson mostra que "ser visível no mundo on-line é, em grande parte, uma questão de ser visível para mecanismos de pesquisa, e acima de tudo 
para o Google" (2013, p. 277). Esses intermediários, portanto, cumprem papel fundamental para que informações sobre o livro circulem, já que quanto mais se fala sobre uma obra na internet, mais chances ela terá de ser lida e de alcançar um bom número de vendas.

O campo visual torna-se, assim, um meio essencial para chamar atenção de leitores para obras impressas, através do crescente número de postagens em redes sociais e vídeos em canais no YouTube. Seja em produtos idealizados por grandes editoras ou pelos próprios autores, as imagens exibidas em plataformas digitais se tornam fundamentais para a dinâmica do meio literário. Assim, não se pode ignorar a importância do conteúdo produzido fora de suportes tradicionais como o livro impresso e o jornal. Na internet e na televisão, autores comentam livros, críticos produzem conteúdo artístico e leitores também fazem crítica literária em blogs, canais no YouTube e outros sites. Junto ao autor, o crítico muitas vezes também participa de feiras literárias e aparece em programas na internet e na televisão.

A discussão sobre um possível esgotamento da crítica se renova quando se leva em conta esses novos suportes, que possibilitam sua realização em outros formatos. Nas plataformas digitais, o crítico especializado também pode encontrar espaço para experimentar outras maneiras de trabalhar seus textos. Além disso, também se percebe uma grande quantidade de pessoas não inseridas diretamente no meio literário fazendo papel de críticos e dialogando com um grande número de leitores. Diz o escritor e crítico literário Miguel Sanches Neto:

Houve tal proliferação de análises, desde obras clássicas à última postagem em um blog, que já não se sabe o que é ensaio, o que é crítica de rodapé, o que é resenha jornalística ou o que é mera opinião. A abertura dos espaços de expressão permite que se publique um longo texto com intenções acadêmicas e que, no mesmo site ou blog, isso gere comentários de leitores, com recusa, aprovação ou complementação do debate. (...) Há uma contaminação de discursos, um rebaixamento ou uma elevação de abordagens, da agressão preconceituosa a pequenas réplicas de aulas sobre o tema, transformando o mundo digital num terreno fértil para aquilo que, no passado, na era de ouro dos suplementos literários, poderia ser definido como "crítica viva", na feliz definição de Antonio Candido. (2012)

Quando se fala da internet e das mudanças que possibilita no meio literário, deve-se considerar, então, a possibilidade de mais pessoas terem acesso às obras já canonizadas e também de conquistarem visibilidade para o material que venham a produzir, utilizando de modo criativo e criticamente as ferramentas oferecidas pelas plataformas digitais. A presença de críticos e autores em diferentes plataformas não deve, assim, ser, necessariamente, avaliada como negativa. É importante, no entanto, chamar atenção para o fato de que a migração dessas figuras para o ambiente digital tem sido, por vezes, protagonizada pelas grandes 
empresas do meio editorial e servido mais a seus interesses econômicos do que ao objetivo de divulgar produtos esteticamente inovadores para o público ampliado presente nas redes.

Nesse ponto, cabe lembrar a mudança ocorrida na atuação dos chamados booktubers influenciadores digitais que utilizam o Youtube para produzir conteúdos voltados para a literatura. A popularização dessa prática de recomendação de livros por leitores comuns, não necessariamente especializados, isto é, por indivíduos que se apresentam como amadores, chamou a atenção das editoras. Algumas, diante do grande número de seguidores de determinados booktubers, passaram a remunerá-los para que divulgassem, com avaliação positiva, livros por elas editados. A partir daí, alguns perfis começaram a incluir links de empresas como, por exemplo, a Amazon. para compra das obras comentadas, o que desencadeou reações negativas por parte do público.

Como se pode constatar, interagindo com outras instâncias, como a da crítica e a do mercado editorial. as imagens ganham cada vez mais destaque no campo literário. No computador, os textos não são os únicos responsáveis por chamar atenção do público para uma obra, o que exige que se repense o lugar não só do crítico tradicional, que antes escrevia prioritariamente para veículos como revistas e jornais impressos, mas também o da publicidade, que passa a utilizar outras estratégias, levando em conta algumas das particularidades do meio digital.

Segundo Roger Chartier, estamos vivendo uma mutação sem precedentes no que diz respeito à prática da leitura/escritura, pois afetam, ao mesmo tempo, os suportes da escrita, as técnicas de reprodução, de disseminação e os modos de ler. Tal simultaneidade, de acordo com o historiador, seria inédita na história da humanidade: a invenção da imprensa não modificou as estruturas fundamentais do livro, composto, depois como antes de Gutenberg, por cadernos, folhetos e páginas, reunidos em um mesmo objeto, assim como a forma nova do livro, nos primeiros séculos da era cristã, a do códex, se impôs em detrimento do rolo, porém não foi acompanhada por uma transformação da técnica de reprodução dos textos, sempre assegurada pela cópia manuscrita $(2010$, p.8).

Os Estudos Visuais têm, assim, nas práticas literárias contemporâneas, um campo fértil para investigação, numa época em que, por exemplo, a publicidade, enviada por email, da empresa Design do Escritor Editorial, vendendo o booktrailer de livros, é a seguinte:

Promova seu livro como um trailer de cinema em toda internet! Uma maneira sofisticada, divertida. Desenvolvido com software usado pelos estúdios de Hollywood. Um texto pode passar despercebido, mas um booktrailer não. Uma maneira que atrai e demonstra profissionalismo. 
No mesmo sentido, também cabe lembrar o projeto intitulado sugestivamente "Assista a esse livro", lançado pela TV Globo com a minissérie Dois irmãos, em 2016. O projeto pressupõe, além da adaptação de obras literárias para a TV, a publicação, em parceria com a editora Companhia das Letras, de ebooks hiperlinkados, através dos quais o leitor poderá mergulhar no universo da história não só através do texto, mas também assistindo às cenas exibidas pelo canal de televisão na adaptação da obra. Cada livro digital contém links de vídeos com duração de até um minuto. $\mathrm{Na}$ apresentação da minissérie, o diretor de Comunicação da Globo, Sérgio Valente, declarou:

Os livros contam histórias que, na televisão, ficam ainda mais vivas e tomam forma não apenas na cabeça de quem lê, mas na cabeça de quem vê. E isso ajuda a despertar o desejo pela literatura. Eu, por exemplo, não tinha lido Dois Irmãos. E ao ver o trabalho brilhante feito por Luiz Fernando Carvalho e Maria Camargo, me deu uma profunda curiosidade de descobrir a obra de Milton Hatoum. Pra mim, isso foi um presente. ${ }^{5}$

Vale lembrar que o diálogo da literatura com o campo visual tem se expandido também com a crescente publicação de narrativas em quadrinhos inspiradas em obras clássicas. Na Comic-Con de 2016, a HQ Dois irmãos, de Fábio Moon e Gabriel Bá, baseada no romance de Hatoum, ganhou o prêmio de "melhor adaptação de outro meio". O prêmio, considerado um dos mais importantes do mundo para os quadrinhos, não foi o primeiro desses quadrinistas, que também ganharam o Jabuti por uma adaptação de "O alienista", de Machado de Assis, em 2008. Para continuar citando exemplos brasileiros, além desses livros, também Grande sertão: veredas, de Guimarães Rosa, foi adaptado para os quadrinhos em 2014 por Eloar Guazzelli Filho, tendo sido premiado no Jabuti do ano seguinte.

Além disso, há a valorização crescente dos chamados livros-objeto como um dos efeitos do diálogo do literário com o campo visual. Observa-se, atualmente, um aumento de importância do design no meio editorial, atribuindo outros valores ao livro físico, chamandose a atenção para as propriedades do suporte. Apesar de sabermos que o mercado editorial sempre recorreu a profissionais desse campo para elaborar capas, ilustrações e diagramar textos, vem se tornando mais comum a utilização do design para a construção de livros de gêneros diversos que pretendem ser identificados como objetos de arte.

Expande-se, inclusive, a publicação de livros cujo trabalho na esfera plástica complementa a própria trama da obra, como é o caso de $S$, escrito por de Doug Dorst a partir

\footnotetext{
${ }^{5}$ Declaração publicada na matéria "Globo lança a série Dois Irmãos”, de Endrigo Annyston. Disponível em https://observatoriodatelevisao.bol.uol.com.br/noticia-da-tv/2016/12/globo-lanca-a-serie-dois-irmaosdramaturgia-diferente. Acesso em 6 de março de 2017.
} 
de projeto de J.J Abrams (2015): este último, diretor e roteirista de vários filmes e séries de sucesso, dentre eles Star Wars: O despertar da força (2015). S é o título que vem impresso na caixa que contém o romance chamado $O$ navio de Teseu, assinado por V.M. Straka, um autor fictício, e "publicado" em 1949. O volume vem com o carimbo de uma biblioteca escolar na folha de rosto, sugerindo-se que teria sido extraviado da instituição. Nele, encontram-se anotações de leitores, também fictícios, nas margens das páginas, que são amareladas para simular o envelhecimento do objeto. As anotações de cada personagem-leitor apresentam caligrafias diferentes e formam uma outra trama que dialoga com o restante do conteúdo do livro. Além disso, encartes, cartões portais e outras imagens que se relacionam com as trajetórias dos personagens podem ser encontradas dentro do livro. Nesse caso, o projeto editorial, a composição gráfica, é tão importante quanto o texto para o desenvolvimento da história.

\section{CONSIDERAÇÕES FINAIS}

Como se vê, a recuperação da imagem contra os iconoclastas une, na contemporaneidade, os artistas, os filósofos, os profissionais da grande mídia e o mercado, o que nos remete para o pensamento de Flusser: segundo ele, a relação texto-imagem é fundamental para a compreensão da história do Ocidente (2002, p.10). E na "longa batalha entre imagem e escrita, entre idolatria e textolatria", textos se tornaram "cada vez mais imaginativos e imagens se tornaram cada vez mais conceituais" (2002, p.10).

Entretanto, se como quer o filósofo tcheco, a letra teria sido inventada para organizar em linhas a magia dos mitos, pode-se partir dessa metáfora provocadora para perguntar, até que ponto, a tomada de posição dos entusiastas da virada visual a favor das imagens - como um outro sempre rebaixado pela metafísica que sustentava a primazia do linguístico - estaria relacionada, hoje, com o fato de, cansados de progresso e descrentes da história, termos nos deixado seduzir, em alguma medida, pela tentação de retorno a uma consciência mágicomítica.

Nesse caso, ao assumir uma defesa radical das imagens, estaríamos correndo o risco de invalidar a crítica política e ética das práticas culturais na sociedade midiática? Ou ainda: o reconhecimento emergente da primazia das imagens como rastros que escapam à programação dos códigos lineares nos levaria a fazer tábula rasa de outros tipos de programação, como, por exemplo, a das tecnologias que medeiam a experiência visual, no mundo contemporâneo? 


\section{REFERÊNCIAS}

BREA, José Luis (Ed.). Estudios Visuales: la epistemología de la visualidad en la era de la globalización. Madrid: Akal, 2015.

CHARTIER, Roger. A ordem dos livros. Brasília: UNB, 1999.

CHARTIER, Roger. Os Desafios da Escrita. São Paulo: Unesp, 2002.

CHARTIER, Roger. Escutar os mortos com os olhos. Revista Estudos Avançados vol.24, n 69, São Paulo, USP, 2010.

FIGUEIREDO, Vera Lúcia Follain de. Narrativas migrantes: literatura, roteiro, cinema. Rio de Janeiro: PUC-RIO/7Letras, 2010.

FLUSSER, Vilém. Filosofia da Caixa Preta: ensaios para uma futura filosofia da fotografia. Rio de Janeiro: Relume Dumará, 2002.

GENETTE, Gérard. Paratextos editoriais. São Paulo: Ateliê Editorial, 2009.

HAYLES, N. Katherine. Literatura Eletrônica: novos horizontes para o literário. São Paulo: Global: Fundação Universidade de Passo fundo, 2009.

LEJEUNE, Phillippe. O pacto autobiográfico: de Rousseau à internet. Belo Horizonte: UFMG, 2008.

MITCHELL, W.J.T. Showing seeing: a critique of visual culture. Journal of Visual Studies (London), v.1, n.2, p. 165-82, 2002.

MITCHELL, W.J.T. O que as imagens realmente querem. In: ALLOA, Emanuel (Org). Pensar a imagem. Rio de Janeiro: Autêntica, 2015.

MOXEY, Keith. Nostalgia de lo real. Revista Estudios Visuales: Los Estudios Visuales en el Siglo XXI, diciembre 2003.

NETO, Miguel Sanches. Crítica e redes sociais. Jornal Rascunho, janeiro de 2012. Disponível em <http://rascunho.com.br/critica-e-redes-sociais/> Acesso 28 julho. 2016.

RANCIÈRE, Jacques. Sobre políticas estéticas. Barcelona: Museu d'Art Contemporani de Barcelona: Servei de Publicacions de la Universitat Autónoma de Barcelona, 2005.

RICHTER, Gerhard (ed.). Benjamin's Ghosts: Interventions in Contemporary Literary and Cultural Theory. Stanford: Stanford University Press, 2002.

THOMPSON, John B. Mercadores de cultura. São Paulo: Editora Unesp, 2013.

WAJCMAN, Gérard. El ojo absoluto. Buenos Aires: Manantial, 2011. 
Doutora em Letras. Professora do Programa de Pós-Graduação em Comunicação da Pontifícia Universidade Católica do Rio de Janeiro e pesquisadora do CNPq. Autora, dentre outros trabalhos, dos livros: A ficção equilibrista: narrativa, cotidiano e política, Narrativas migrantes: literatura, roteiro e cinema, Os crimes do texto: Rubem Fonseca e a ficção contemporânea e Da profecia ao labirinto: imagens da história na ficção latino-americana.

Marina Burdman da Fontoura

Doutoranda em Comunicação Social pela PUC-Rio. Mestre em Literatura, Cultura e Contemporaneidade e graduada em Comunicação Social (Jornalismo) também pela PUC-Rio. Foi bolsista-pesquisadora do projeto Cultura Brasileira Hoje, da Fundação Casa de Rui Barbosa.

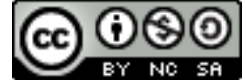

Esta obra está licenciada com uma Licença

Creative Commons Atribuição-NãoComercial-CompartilhaIgual 4.0 Internacional 